
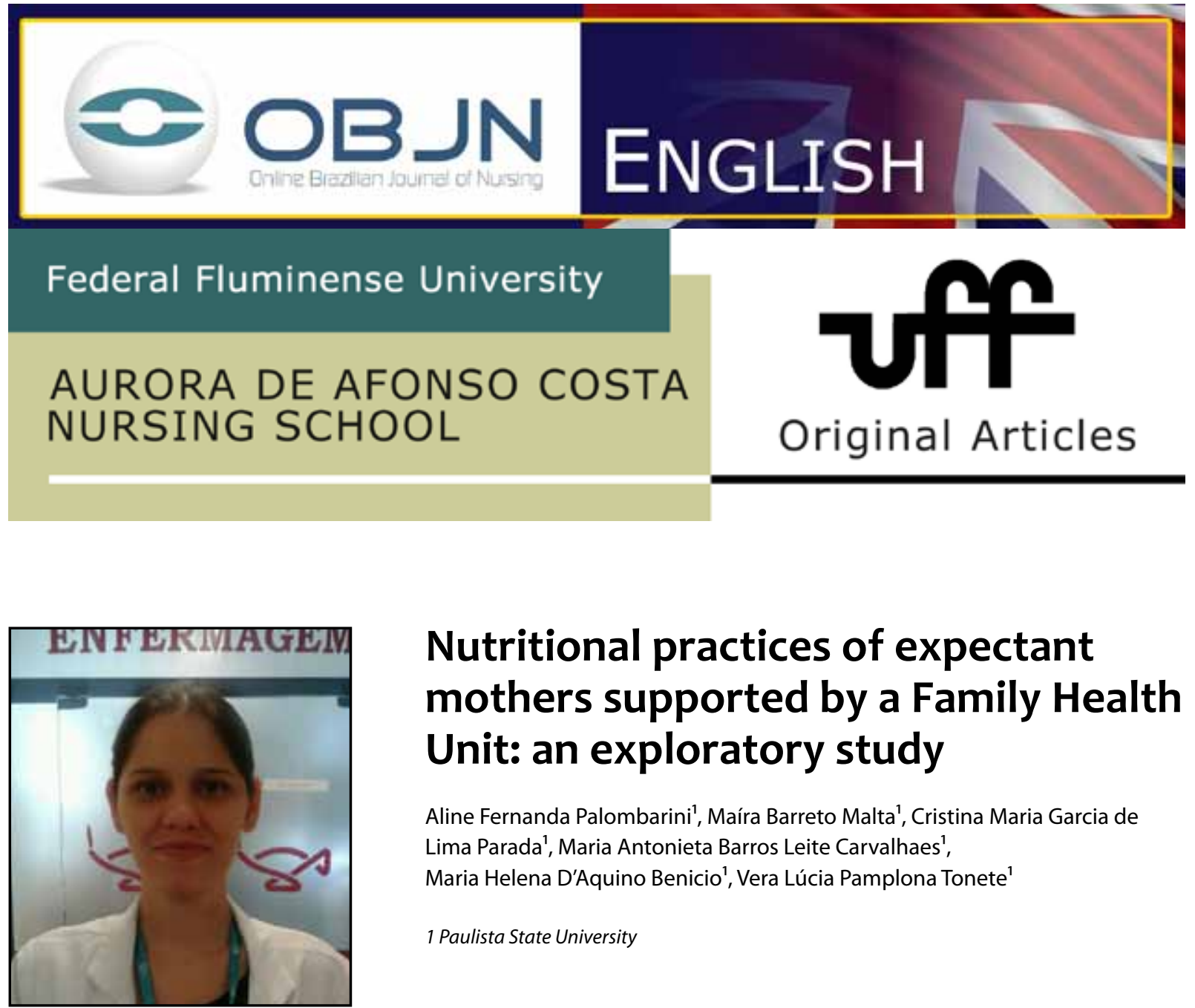

\title{
Nutritional practices of expectant mothers supported by a Family Health Unit: an exploratory study
}

\author{
Aline Fernanda Palombarini', Maíra Barreto Malta', Cristina Maria Garcia de \\ Lima Parada', Maria Antonieta Barros Leite Carvalhaes', \\ Maria Helena D'Aquino Benicio', Vera Lúcia Pamplona Tonete ${ }^{1}$ \\ 1 Paulista State University
}

\section{ABSTRACT}

Aim: to identify the concepts regarding dietary practices among low income expectant mothers, and to understand the subjective aspects involved on their daily dietary practices. Method: this is an exploratory study, based on the theoretical reference of the Comprehensive Sociology of Everyday Life, performed with twelve pregnant women supported in a family health unit. The data was collected through semi-structured interviews, and treated according to the method of content analysis, using the thematic approach. Results: for the expectant mothers, their diet must be healthy, paying attention to its composition and schedule, however that is not always possible. They are given information and start having better nutrition during pre-natal care, but on the other hand, they need support from health services when facing difficulties. Discussion: the influence of life context was confirmed over the nutrition of expecting mothers, as well as the relevance of individual discipline and willpower towards a healthy nutrition. Conclusion: the adequate nutritional intervention must consider subjective factors that influence the way pregnant mothers have their diet and have their dietary choices.

Descriptors: Pregnancy; Feeding; Family Health. 


\section{INTRODUCTION}

Pregnancy is not only a physiological occurrence in the life of a woman, but also has social implications, for the pregnant woman, her family and society. Pregnancy is, therefore, an intensively personal experience, that can lead to questions concerning emotional and cultural influences, such as those relating to spiritual practices and beliefs, changes in a woman's body and self-image, the issue of maternal weight gain, performance of physical activities and abortion among others ${ }^{(1)}$.

Dietary practices during pregnancy, the topic of this study, are one essential element in the promotion of maternal and child heal$t^{(1,2)}$. During pre-natal care, the health team is tasked with informing an expectant mother of the scientific and technical aspects surrounding healthy pregnancy, which includes the topic of nutrition. This intervention can encourage expectant mothers to contemplate their own concepts and beliefs regarding the topic. Scientific understanding of good nutritional practice and the cultural beliefs of the expectant mother can overlap, clash or agree, thus potentially challenging her autonomy over her dietary choices ${ }^{(2)}$.

Therefore, a mother's subjective beliefs about nutrition may lead to problematic dietary practices, highlighting the importance of the relationship between health professionals and mothers in this area. The aim of this relationship should be to encourage both parties to build a shared information base regarding dietary practices ${ }^{(3)}$.

With view to acquiring funding for a subsequent health action plan targeting expectant mothers, this study was developed to obtain the active participation of this group in informing this plan. The following questions were developed: What do the ex- pectant mothers who are supported by family health unit (FHU) know about nutrition during pregnancy? What is the current state of their everyday nutrition?

The established objectives were: to identify nutrition-related concepts among low-income expectant mothers and to understand subjective influences on the daily dietary practices.

\section{METHOD}

This is a qualitative study ${ }^{(4)}$ with exploratory aspects, based on the theoretical underpinnings outlined in the Comprehensive Sociology of Everyday Life by Michel Maffesoli(5). This study forms part of a wider investigation entitled"The impact of intervention to promote jogging and health nutrition in expectant mothers supported by Family Health Strategy program: a controlled cohort study" (Protocol FAPESP 2011/18579).

A qualitative methodology was chosen given that this study was concerned with exploring relationships, views and opinions and meanings. Human beings not only express attitudes, but also consider the actions they take and interpret them based on individual experience. Hence, the qualitative methodology is appropriate when searching for phenomena pertaining to social actors, to the meaning that they give to objects and to the social actions that they perform ${ }^{(4)}$.

Qualitative studies in the area of Comprehensive Sociology propose that subjectivity is an inherent part of social interactions. Therefore, the present study is not interested in objective quantification, but instead tries to explain aspects of social relations by considering them as the product of creative, affectionate and rational human activity. 
These relations are expressed through experiences in everyday life, and common sense explanations will be offered ${ }^{(4)}$.

According to the Comprehensive Sociology of Everyday Life, society is not only a mechanistic economical-political or social system, but is also a set of interactive actions involving affection, emotions and sensations that are, to translate exactly, the "social body"(5). According to Michel Maffesoli, Comprehensive Sociology aims to describe experiences as they are seen, and tries to understand the different views of the people involved. In other words, for this author, this approach is adequate to show the limits and the necessities in situations and representations that constitute the everyday life of people and their interactions ${ }^{(5)}$.

To participate in this study, expectant mothers registered and supported by a FHU in a medium-size city, located north of the Brazilian state of São Paulo. These expectant mothers had to be in the second trimester or later of their first pregnancy, 18 years old or older with no record of previous disease (diabetes, hypertension, heart diseases) or any other adverse condition that would require a specialist dietary routine.

The sample size of this study ( $\mathrm{N}=12)$ was considered adequate to allow for the data saturation criterion to be met ${ }^{(6)}$. Data saturation was identified when analyzing the data, where it could be seen that no new data was emerging. This demonstrates that sufficient information had been collected to achieve the established goals.

From January to March 2012, expectant mothers who were scheduled for a pre-natal care follow-up consultation at the aforementioned FHU were invited to participate in this study by the researcher following their consultation. The consultation was performed by another professional. Those who agreed to participate, and who fitted the inclusion criteria above, were interviewed in the unit. All the expectant pregnant mothers who were invited to participate, as well as agreed with the proposal of this research, took part in this study. It is important to mention that, at the time of data collection, the researcher was a full-time intern at the unit because of credits needed for her accreditation during a multi-professional residency in family health.

The data was collected using semi-structured interviews ${ }^{(4)}$ recorded in MP3 format, which were later transcribed and deleted.

Content Analysis was used to explore the data, taking a thematic approach composed by three stages: pre-analysis; material exploitation; treatment of the results acquired, inference and interpretation. During the first stage - the pre-analysis -selected materials were read in order to gain a general overview of the setting, focusing on the particularities of the material observed, selecting formats for initial classification and defining the theoretical concepts that will guide the analysis. During the second stage - the exploration of the material - a content analysis was done. This involved classifying sentences in each text, regrouping parts of the text by topics and trying to give meaning using theoretical concepts. The third stage - the treatment of results/inference/interpretation - involved interpreting the results in relation to the objectives, questions and presuppositions of the research ${ }^{(7)}$.

According to Brazilian and international standards of researches with human beings, this study was approved by the Committee of Ethics in Research, of the Botucatu Medicine School, under protocol CEP number 3989-2011. Before the interviews, the expectant mothers were informed about the aims and procedures 
involved in this research. After that, they signed the Free and Clear Consent Agreement.

\section{RESULTS}

The socio-demographic profile of the group of expectant mothers interviewed was between 18 and 27 years old, seven of them $(58.3 \%)$ had eight or more years of school, nine (75\%) were not working and six (50\%) had a fixed partner. In regards to the pregnancy, seven (58.3\%) were multiparous, all were using low risk public service pre-natal care, and at the time of the interview, ten (83.3\%) were in their third trimester of pregnancy.

The testimonies of the expectant mothers are presented in a descriptive format, classified according to the two topics studied, and to the respective central meanings that they belong to. The nuclei of meanings are associated to the units of registration, which are used to generate an identity code for each expectant mother interviewed (E1... E12).

Topic 1 - Concepts about Healthy Nutrition during Pregnancy

1.1 The nutrition of the pregnant mother must be healthy for her and for the baby

Based on the point of view of the interviewees, the nutrition during pregnancy must be healthy for both the mother and the baby, should be better than at other points in the woman's life:

"I think that the mother has to eat better, I think, better than when we eat when we are not pregnant. We have to eat for two. Eat for the mother and for the child[...]" E8
And to do so, according to the testimonies, this nutrition needs to contain certain food types, namely fruits and vegetables, meat and dairy:

"The nutrition of the mother must be healthy. We have to eat a lot of fruits, vegetables[...]" E1

"You have to eat well! Fruits, vegetables, meat, fish[...]" E11

"The nutrition must include all vitamins the baby needs... You have to have fiber, calcium, all... You got to drink milk, have some cheese[...]"E12

Some of the interviewees stated that, besides these aforementioned foods, the nutrition of the pregnant mother must be balanced and scheduled, including the ingestion of liquids, especially those considered natural:

\begin{abstract}
"Nutrition must be balanced, you have to balance vegetables, meat... And you have to drink lots of water, natural liquids... Fruits. This is really important for the baby, not only for the mother[...]"E4
\end{abstract}

"You have to eat every three hours... And you cannot skip breakfast, lunch and dinner[...]" E6

"And you shouldn't eat too much." E11

With the objective of clarifying concepts about healthy nutrition during pregnancy, the interviewees also reported those types of food that should not be consumed, or 
that should be consumed carefully during this period:

"First, the pregnant mother must avoid soda, exaggerate eating some candy, chocolate... I really think you shouldn't have Coca-Cola, which can provoke intestinal gases in the child, leading to cramps in the baby, and that is not good for him. Then, the pregnant mother must give in to the desires she has, but also think what will affect the baby." E1

"I think you should avoid fried foods." E2

"Fried snacks... I think people should forbid these things... They say they are too fattening and they are bad for the child! And you shouldn't eat too much fat, you know?" E7

"And you know, those sandwich cookies are not good for the pregnancy, full of sugar. They may interfere with your blood, generating anemia in the mother and in the baby as well... And that may affect the development of the baby." E12

1.2 You do not always have healthy food available during pregnancy

Interviewees' views on nutrition during pregnancy revealed a number of barriers to a healthy diet, especially those relating to the attitude or disposition of the pregnant mother herself:

"Laziness of the pregnant mother, because there are some people who are simply lazy and are not worried about buying healthy things. E1

I think it depends too much on the person wanting to have a healthier diet, I think. I think that it depends on the pregnant mother to eat well, have a healthy diet. I think it's all on her." E2

"You have to make an effort to eat well." E3

"Well, I think nothing stops you from eating healthy. It depends only if the person really wants it or not." E4

On the other side, ideas about a lack of financial resources as barrier to healthy diet is also present in the testimonies of the pregnant women:

\begin{abstract}
"The lack of resources... The lack of money. Suddenly, there is unemployment... You need adequate financial conditions." E5
\end{abstract}

"Sometimes, I don't have the conditions to... I don't know..." E10

Besides that, the unpleasant symptoms inherent to pregnancy were also mentioned as possible obstacles to proper nutrition:

\footnotetext{
"But there are some mothers that cannot eat at all, they feel sick[...]"E3

"I think that the nausea complicates a proper diet, only that..." E9
}
Topic 2-Experiences of Nutrition during Preg- nancy


2.1 I got information about healthy nutrition for the expectant mothers in different moments and places

When considering interviewees' experiences of their own nutritional practices, they were asked about sources of information they had received and discussions they had had on the topic of nutrition during pregnancy. These were often addressed during the moments they were present at the health unit, during actual pre-natal care consultations, and in some cases, during previous pregnancies:

“So, I didn't know anything about it. I learned reading the pamphlets I was given during my first consultation." E1

"During the consultations, the physicians and the nurses of the unit approached me." E4

"With my first physician, when I had my first daughter. I was basically a child taking care of another one." E5

"At the unit they give us some information. Then we have to follow the rules to have a healthy pregnancy." E6

They also mentioned that they discussed this topic with relatives and other members of their community:

\footnotetext{
"My grandmother tells me all the time to not eat fried snacks and have more fruits, to think about my child." E7

"I learned looking at my own family... My mother, my aunts." E8
}

"I learned through the workshop I attended, with the nurses." E12

\subsection{During pregnancy, I started to eat better, however I can do better}

Regarding nutrition during pregnancy, the testimonies that were collected demonstrate the attitudes of the mothers towards adjusting to a new diet, contrasting with their previous nutrition:

\begin{abstract}
"When I found I was pregnant, I knew that I had to have healthy nutrition. Then I started to eat a lot of fruits, three a day, lots of vegetables, especially at night. During lunchtime, I don't have as much, because I work and I bring my meals from home... And at night, I have dinner. In the beginning, I didn't eat much; actually I used to eat very little. Now that I'm eating more, I'm always having fruits and vegetables." E1
\end{abstract}

"Oh! I have rice, beans, cheese, bananas, apple... What I like the most is mango, acerola berry, these kind of things. Vegetables, I only eat lettuce[...] E7

"I think I eat well. From my point-of-view, I don't know if my doctors agree with me, though... My daily routine, before the pregnancy, I used to eat like: I had lunch and dinner, and that's it. Now I have something for brunch, like a biscuit, a piece of bread, a fruit; things I didn't eat! At breakfast, I didn't use to have any, but now I do!" E8 
"Now I'm eating better because I have more things to eat, because before I didn't have enough money to buy anything, but now we do. What I eat really is the traditional diet: rice, beans, meat[...]" E11

According to the interviewees, at the same time they were looking to improve their nutrition, they still faced problems changing their diet and tastes to fit with their idea of healthy nutrition. It is important to see that, in general, the interviewees assumed the responsibility for what they considered nutritional errors:

"Then I stopped a little, but now I have to eat different fruits again, because I am used to always eating the same ones. Then I have to change fruits and change some vegetables as well, because I am sick of those I am used to eating." E1

"I eat according to what... I try to eat every three hours, in small quantities. I think I eat well, but I could improve the fruits and vegetables[...]" E5

"What I need to stop eating is fattening food, cookies and the like." E11

“There are some things I don't have any conditions to buy... But I can make my diet better somehow." E12

2.3 The pregnant mother must have better orientation and support from the health services on healthy nutrition

In accordance to what was already described here, when the mothers were asked about their expectations regarding pre-natal care at the FHU, the interviewees suggested that more attention should be given to the orientations about healthy nutrition, in individual consultations or in group workshops with pregnant women:

"We should talk more, you know? We should discuss... It doesn't matter if the (pregnant) mother says she already (eats well)... Can she really do it? Does she refuse to do it? That's why we have to be always discussing these things, in a way they will understand $[. .]$.$" E1$

\begin{abstract}
"See, I think that we should talk with the women more often, because sometimes there are some mothers that are in doubt: "What can I eat?" So, then, when we do it like that... Talking a little bit more. Motivating the mother to have proper nutrition, to eat better. I think it is more about the orientation you give to increase the mothers' awareness, so they can eat better. That's how I see it." E2
\end{abstract}

"Well, you have to discuss a lot during
the consultations, tell the mothers
they have to eat well, thinking about
the baby." E3

"I think people should have more contact with the pregnant mother, having some meetings at the unit, something like that... A group composed of pregnant mothers, only." E4

"I think that in this topic, there should be some sort of list, to guide, to know what I should eat more and 
what I should avoid completely or partially. E7

Giving hints[...]" E9

"Well, I think they should hand some guidelines, so we can eat better. Like a pamphlet." E11

At the same time, it was suggested that more attention and support needs to be given the socioeconomic issues experienced by the mothers, especially regarding questions relating to having proper nutrition during this period:

"I think that, on the day of consultation, that we spend more time at the unit, there should be some juice, something we could eat... Because I know there are many (mothers) that they usually don't have anything at home. And come to the consultation starving... And they should visit their homes, to see how things are... And that is what the social worker is supposed to do, to see how the conditions of the mothers are, their homes, and to try to give a hand somehow." E5

"I think that, you know... They should help those who have few resources to have proper nutrition, to eat something... I think that, if it was possible, they should provide the pregnant mothers that do not have enough money with basic food. I think it would be very helpful, for both the mother and the child." E12

Regarding this central meaning, the extract taken from the testimony of one single mother demonstrates that, for this subject, available health services have an important and effective role in promoting healthy nutrition during pregnancy, reinforcing that this objective is not fulfilled due to a lack of commitment on the part of the mother:

$$
\begin{aligned}
& \text { "Well, the unit does everything they } \\
& \text { can do! We are the ones that do not } \\
& \text { control ourselves and end up eating } \\
& \text { things we shouldn't eat." E10 }
\end{aligned}
$$

\section{DISCUSSION}

This analysis of the characterization of the interviewees confirmed the expected result: the participants of this study had low socioeconomic status. Conservation of womens' imposed social roles in their families could be seen through the extracts presented, as many of them did not have high school level education and were primarily responsible for all sorts of homecare roles and/or caring for other children. Certainly, the following analysis of the concepts and experiences, identified in this study, need to be taken into account in light of this information. A similar study that took place in the city of Rio de Janeiro( ${ }^{(8)}$ corroborates these findings, confirming that nutrition is not only a health necessity, but also a social issue, as the concepts and experiences of the individuals and society emerge socially and are distinctive in the context which they are presented.

A recent study, with a reflexive approach, exploring the area of nutrition highlights the complexity of relationships involving eating and dieting, and the importance of influencing nutritional orientation, associating the technical understanding of this field with comprehensive theories $^{(9)}$. 
In regards to concepts concerning adequate nutrition during pregnancy, it was seen that the mothers mentioned, from one side, the ingestion of "natural" solids and liquids that were considered healthy and important for a balanced diet, which also included a regular schedule. On the other hand, they mentioned the harmful elements of a diet, such as fattening products, industrialized goods and "snacks", which should not be consumed. These concepts were also seen in a study of low-income women living in the city of Rio de Janeiro, whose interviews drew attention to ideas such as "healthy food", represented by fruits and vegetables, and "fast food" and "snacks", including candies, industrialized goods and fattening products(2).

In this present study, the nurturing mothers drew attention to the importance to adequate nutritional habits when pregnant, in agreement with scientific understanding on the topic ${ }^{(10)}$.

From the moment a pregnancy is confirmed, there is often anxiety surrounding the amount of intensive care that a newborn will demand. However, the mother can feel motivated or not, depending on her desire and the moment of the pregnancy ${ }^{(7)}$. In a systematic review of qualitative and quantitative studies in the topic of weight management during pregnancy, produced all over the world, from 1990 to $2010^{(10)}$, it was seen that through a thematic analysis of qualitative findings that interviewed women viewed pregnancy as a moment of transformation, of transition and of lack of control. This study also demonstrated that pregnancy is seen as a unique moment, in which the necessities of the newborn take precedence over the necessities of the mother. Despites this, women do however demonstrate an ambivalence regarding their nutritional behavior, justifying excess food intake as a temporary situation. It is important to highlight that, in the aforementioned article, the influence of the social context on womens' conceptions was also observed ${ }^{(11)}$.

It is also important to mention that, in all interviews in this present study, nutrition during pregnancy was really appreciated, and reinforced the understanding that dietary changes must occur during this period or that, if the regular diet is already adequate, it should be maintained. The interviewees emphasized the role of discipline and willpower from the pregnant mother in regards to making dietary changes, even though they took into consideration some external barriers to these changes, such the unpleasant symptoms inherent to pregnancy, or even their social and economical status.

As a whole, regarding the experiences of the pregnant women, the testimonies collected revealed that the topic of nutrition during pregnancy was considered part of their routine, as they had many opportunities to get in touch with this issue, either in hospitals or with relatives. It is possible to see that the ideas conceived demonstrated clear influences from scientific findings and from the common sense explanations that the pregnant women were exposed to ${ }^{(12)}$.

In a review of literature mentioned previously(11), it was confirmed that information and advice about nutrition come from three main sources during pregnancy: family and friends, communication, and health professionals. This review ${ }^{(11)}$ also revealed that some healthy habits and behaviors seem to be strongly influenced by the viewpoints from the structures that support for women during their pregnancies. The data collected from this present study add up to such conclusions, demonstrating, at the investigated local context, common characteristics seen worldwide. 
Therefore, to contribute effectively to the proper nutritional consumption of expectant mothers, health services must consider the influence of the local environment on the ways that they eat and the dietary choices that they make. It is important to comprehend their views and, at the same time, promote the required changes in nutritional behavior. Powerful influences on diet are demonstrated, often generated by the family, and there is theoretical, practical and scientific evidence to support the role of the family in promoting acceptance of the idea of good health and well-being $^{(13)}$.

It was also possible to see, in this present study, that among the influences on mothers, health professionals ware an important source of prescriptions and prohibitions.

This research also shows that there may be consequences of rules imposed by the technical, biomedical and sometimes authoritarian side of the health professionals. These rules may be in opposition with the attitude and practices of the expectant mothers based on to their previous experiences. It is therefore essential that the particularities and desires of each expectant mother are taken into account when health professionals and users meet, making sure the interventions are flexible, in order to generate more positive results ${ }^{(14)}$.

The results regarding mothers' expectations about their care demonstrate that the educational information given during the pre-natal care consultations, and organization of educational workshops, can be highly effective ways to inform expectant mothers. Therefore, pre-natal care is an important and privileged moment to contextualize the individual life cycle of the pregnant women, and subsequent discussions about healthier habits.

In fact, educational workshops are known to be a complementary means discussing the health habits of pregnant women, including aspects regarding anxiety and other topics connected to pregnancy through an exchange of experiences ${ }^{(15,16)}$.

From the testimonies, the importance of appropriate care for expectant mothers was highlighted, specifically those in poverty or who are unable to provide for themselves. From one side, some testimonies demonstrated welfarist concerns, whilst on the opposite hand, concepts of autonomy, self-determination and the functional and moral independence of individuals were brought up. There was a strong belief that the health team was in a suitable position to propose alternate strategies to guide and support economically challenged mothers to obtain the adequate nutrition. It is important to mention that anxieties surrounding healthy diets expressed by some expectant mothers were evidence by records of official social policies and programs that have provided them with benefits (food or income complements) to fulfill their needs.

\section{CONCLUSION}

Based on expectant mothers' views regarding nutrition, there was strong recognition of the importance to eating a healthy diet and making healthy changes during this period primarily for the positive consequences of these changes for the baby.

The diets experienced and described by the subjects of this study demonstrated that their nutrition was strongly influenced by aspects of their sociocultural and economic context, however two other important influences were also mentioned: discipline and willpower to achieve healthy nutrition.

The value of moments of discussion about the topic of nutrition during pre-natal 
care consultations was also recognized and the participants in this study viewed this practice as a means of promoting a healthy diet.

A further apparent element was expectant mothers' discernment of their responsibility to know what is best for their health and that of the baby that they are still nurturing. However, it could be observed that they feel the necessity to share their responsibility with the health team that supports them during pre-natal care, in a way that they are stimulated to reflect and discuss on relevant matters, and so together come to develop new understandings and practices.

Considering the theory of the Comprehensive Sociology of Everyday Life, the results of this research indicate that nutritional education activities to support pre-natal care in the FHU, in both individual consultations and in workshops, should be constructed in a participative, reflexive and culturally contextualized format. These interventions should also be tailored to the individual elements of the daily lives of the mothers and should support their personal motivation and the motivation to incorporate healthy practices.

The theoretical framework that was adopted draws attention to the importance, during the analysis of everyday life, of taking into consideration the many different views of the phenomenon under consideration. Hence, the fact this research focused exclusively on their perspectives is a limitation that could be overcome in future investigations that consider the viewpoints of the others.

In conclusion, it is important to highlight that, besides focusing on a specific reality and exploring subjective aspects of dietary practices during pregnancy, it can also bring important contributions regarding nutritional interventions in similar scenarios.

\section{REFERENCES}

1. Jarvis C. Exame físico e avaliação de saúde para enfermagem. $6 a$ ed. Rio de Janeiro: Elsevier; 2012.

2. Baião MR, Deslandes SF. Eating practices during pregnancy: a study of low-income pregnant and postpartum women in Rio de Janeiro (RJ, Brazil). Ciênc. Saúde Coletiva. 2010;15:3199-3206.

3. Saunders C, Santos MAS, Padilha PC. A dietary counseling program and the quality of a prenatal care service. Rev Bras Ginecol Obstet. 2011;33:9-12.

4. Minayo MCS. Pesquisa social: teoria, método e criatividade. $O$ desafio do conhecimento: pesquisa qualitativa em saúde. 29a ed. Petrópolis: Vozes; 2010.

5. Maffesoli, M. O conhecimento comum: introdução à sociologia compreensiva. Porto Alegre: Sulina, 2010.

6. Fontanella BJB, Ricas J, Turato ER. Saturation sampling in qualitative health research: theoretical contributions Cad. Saúde Pública. 2008;24(1):17-27.

7. Bardin L. Análise de conteúdo. 5a ed. Lisboa: Edições 70; 2010.

8. Baião MR, Deslandes SF. Pregnancy and eating behavior in pregnant women from a low-income neighborhood in Rio de Janeiro, Brazil. Representações sociais sobre alimentação e práticas alimentares de gestantes e puérperas. Cad. Saúde Pública. 2008;24(11):2633-2642.

9. Freitas MCS, Minayo MCS, Fontes GAV. The field of Food and Nutrition from the perspective of comprehensive theories. Ciênc. Saúde Coletiva. 2011;16(1):31-38.

10. Cotta RMM, Costa GD, Reis RS, Sant'Ana LFR, Rodrigues JFC, Castro FAF, Campos ACM. Aspectos relacionados aos hábitos e práticas alimentares de gestantes e mães de crianças menores de dois anos de idade: o programa saúde da família em pauta. O Mundo da Saúde. 2009;33(3):294-302.

11. Campbell F, Johnson M, Messina J, Guillaume L, Goyder E. Behavioural interventions for weight management in pregnancy: A systematic 
review of quantitative and qualitative data. BMC Public Health 2011;11:491.

12. Brasil. Ministério da Saúde. Secretaria de Atenção à Saúde. Departamento de Atenção Básica. Atenção ao pré-natal de baixo risco/ Ministério da Saúde. Secretaria de Atenção à Saúde. Departamento de Atenção Básica. Brasília: Editora do Ministério da Saúde, 2012. 318 p.: il. - (Série A. Normas e Manuais Técnicos) (Cadernos de Atenção Básica, $n^{\circ} 32$ ).

13. Wright LM, Leahey M. Enfermeiras e famílias: um guia para avaliação e intervenção na família. 5a ed. São Paulo: Roca; 2012.

14. Budó MLD, Mattioni FC, Machado TS, Ressel LB, Lopes LFD. Quality of life and health promotion through the perspective of the users of the family health strategy. Online Braz J of Nurs. [periodic on the Internet]. 2008 [accessed on 2013 Feb 26] 7(1). Available from: http://www.objnursing.uff.br/index.php/nursing/article/view/j.1676-4285.2008.1104/291

15. Klein MMS, Guedes CR. Psycological pregnants' intervention: support group contributions for health promotion. Psicologia, ciência e profissão. 2008;28(4):862-871.

16. Santos MMAS, Saunders C, Baião MRR. Interpersonal relations between health professional and pregnant adolescents: distances and approaches of integral and humanized care. Ciênc. Saúde Coletiva. 2012;17(3):775-786.

Contribution from the authors:

Aline Fernanda Palombarini participated in concept, data collection, analysis and interpretation of results and writing of the paper.

Maíra Barreto Malta participated in analysis and interpretation of results and writing of the paper.
Cristina Maria Garcia de Lima participated in analysis and interpretation of results and writing of the paper.

Maria Antonieta Barros Leite Carvalhaes participated in analysis and interpretation of results and writing of the paper.

Maria Helena D'Aquino Benicio participated in analysis and interpretation of results and writing of the paper.

Vera Lúcia Pamplona Tonete participated in concept, analysis and interpretation of results and writing of the paper.

All the authors approved the final version of this paper.

All authors participated in the phases of this publication in one or more of the following steps, in According to the recommendations of the International Committee of Medical Journal Editors (ICMJE, 2013): (a) substantial involvement in the planning or preparation of the manuscript or in the collection, analysis or interpretation of data; (b) preparation of the manuscript or conducting critical revision of intellectual content; (c) approval of the versión submitted of this manuscript. All authors declare for the appropriate purposes that the responsibilities related to all aspects of the manuscript submitted to OBJN are yours. They ensure that issues related to the accuracy or integrity of any part of the article were properly investigated and resolved. Therefore, they exempt the OBJN of any participation whatsoever in any imbroglios concerning the content under consideration. All authors declare that they have no conflict of interest of financial or personal nature concerning this manuscript which may influence the writing and/or interpretation of the findings. This statement has been digitally signed by all authors as recommended by the ICMJE, whose model is available in http://www. objnursing.uff.br/normas/DUDE_eng_13-06-2013.pdf

\footnotetext{
Received: $02 / 26 / 2013$

Revised: 03/26/2014

Approved: 04/29/2014
} 